\title{
Carrier concentration induced band-gap shift in Al-doped Zn1- xMgxO thin films
}

\section{AUTHOR(S):}

Lu, JG; Fujita, S; Kawaharamura, T; Nishinaka, H; Kamada, Y; Ohshima, T

\section{CITATION:}

Lu, JG ...[et al]. Carrier concentration induced band-gap shift in Aldoped Zn1-xMgxO thin films. APPLIED PHYSICS LETTERS 2006, 89(26): 262107.

\section{ISSUE DATE:}

2006-12-25

URL:

http://hdl.handle.net/2433/39692

\section{RIGHT:}

Copyright 2006 American Institute of Physics. This article may be downloaded for personal use only. Any other use requires prior permission of the author and the American Institute of Physics. 


\title{
Carrier concentration induced band-gap shift in Al-doped $\mathrm{Zn}_{1-x} \mathrm{Mg}_{x} \mathrm{O}$ thin films
}

\author{
J. G. Lu ${ }^{\text {a) }}$ and S. Fujita ${ }^{\text {b) }}$ \\ International Innovation Center, Kyoto University, Katsura, Nishikyo-ku, Kyoto 615-8520, Japan \\ T. Kawaharamura, H. Nishinaka, Y. Kamada, and T. Ohshima \\ Department of Electronic Science and Engineering, Kyoto University, Katsura, Nishikyo-ku, \\ Kyoto 615-8510, Japan
}

(Received 26 July 2006; accepted 21 November 2006; published online 27 December 2006)

\begin{abstract}
Transparent conducting Al-doped $\mathrm{Zn}_{1-x} \mathrm{Mg}_{x} \mathrm{O}$ thin films were grown on glass substrates by chemical vapor deposition. The resistivity could be lowered to $10^{-3} \Omega \mathrm{cm}$ with optical transmittance above $85 \%$ in visible regions. The influence of carrier concentration on band-gap shift in $Z_{1-x} \operatorname{Mg}_{x} \mathrm{O}$ alloys was systematically studied. The shift of energy gap could be fully explained by the Fermi-level band filling and band-gap renormalization effects. As the $\mathrm{Mg}$ content increased, the electron effective masses in $\mathrm{Zn}_{1-x} \mathrm{Mg}_{x} \mathrm{O}(x=0-0.21)$ alloys increased from $0.30 m_{0}$ to $0.49 m_{0}$. The Al-doping efficiency was reduced with the increase in alloy composition. (C) 2006 American Institute of Physics. [DOI: 10.1063/1.2424308]
\end{abstract}

In the past decades, several research efforts on wide-gap semiconductors have led to the commercialization of devices based on group-III nitrides. As an alternative to the GaN system, $\mathrm{ZnO}$ is attracting substantial attention. The group-II oxide has a large exciton binding energy of $60 \mathrm{meV}$ (cf. $25 \mathrm{meV}$ for $\mathrm{GaN}$ ), which favors efficient excitonic emission processes at room temperature and enables devices to function at a low threshold voltage. ${ }^{1}$ Success in $p$-type doping of $\mathrm{ZnO}$ presented recently may open the door for optoelectronic device fabrication. ${ }^{2}$ Alloying $\mathrm{ZnO}$ with $\mathrm{MgO}$ allows the tuning of the direct band gap into extremely short-wavelength regions. The resultant $\mathrm{Zn}_{1-x} \mathrm{Mg}_{x} \mathrm{O}$ ternary alloy is an ideal transparent conducting oxide (TCO) for use in optoelectronic devices, facilitating band-gap engineering for heterostructure device design, and may eventually compete with the groupIII nitrides. For optoelectronic device applications, knowledge of $n$-type $\mathrm{Zn}_{1-x} \mathrm{Mg}_{x} \mathrm{O}$ is essential. However, in contrast to the well-reported undoped $\mathrm{Zn}_{1-x} \mathrm{Mg}_{x} \mathrm{O}$ films ${ }^{3-5}$ the study on donor doping in $\mathrm{Zn}_{1-x} \mathrm{Mg}_{x} \mathrm{O}$ is very limited. ${ }^{6}$ As a widegap semiconductor, addition of impurities often induces dramatic changes in its optical and electrical properties. For example, the band-gap widening or narrowing due to donor doping has an important influence on physical properties and device performance in semiconductors, but such characteristics of $\mathrm{Zn}_{1-x} \mathrm{Mg}_{x} \mathrm{O}$ alloys have been unknown so far. In this letter, we demonstrate the fundamental properties of Aldoped $n$-type $\mathrm{Zn}_{1-x} \mathrm{Mg}_{x} \mathrm{O}$ thin films.

Al-doped $\mathrm{Zn}_{1-x} \mathrm{Mg}_{x} \mathrm{O}\left(\mathrm{Zn}_{1-x} \mathrm{Mg}_{x} \mathrm{O}: \mathrm{Al}\right)$ thin films were prepared by a chemical vapor deposition (CVD) system. Two starting solutions $(0.1 M)$ were prepared using zinc acetate dihydrate and magnesium acetate tetrahydrate diluted in deionized water. They were mixed in different proportions to form the spraying solutions, with the $\mathrm{Mg}$ contents of $0,4,7$, 10 , and 15 at. \%, respectively. Doping with $\mathrm{Al}$ was achieved by adding aluminum acetate basic to the spraying solution in the range from 0 to 7 at. $\%$ in relation to the $(\mathrm{Zn}+\mathrm{Mg})$ content in this solution. A few drops of hydrochloric acid were

\footnotetext{
${ }^{a)}$ Electronic mail: jglu@iic.kyoto-u.ac.jp

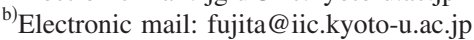

added to prevent any precipitation. The solution was ultrasonically atomized, and the misted vapor was transported to the substrate using $\mathrm{N}_{2}$ as the carrier gas. The desired films were produced on glass substrates at $450{ }^{\circ} \mathrm{C}$ in 1 atm pressure.

The crystal structures of films were investigated by $\mathrm{x}$-ray diffraction (XRD) measurements. The chemical compositions were analyzed by an energy dispersive $\mathrm{x}$-ray (EDX) spectroscopy. The electrical properties were measured in the van der Pauw configuration using a ResiTest 8300 system. The optical transmission and absorption through film were carried out on a Shimadzu UV-3100PC UV-visible dualbeam spectrophotometer, with a bare glass in the reference beam. The effect of the glass substrate may thus be eliminated by the measurement system for using a standard thin film equation.

XRD observations (not shown here) showed that all our films obtained by this system had a polycrystalline structure with a preferential $c$-axis orientation. EDX analyses (not shown here) revealed that the $\mathrm{Mg}$ content in the film was systematically higher than that in the solution by a factor of about 1.5 , while the amount of $\mathrm{Al}$ in the film was nearly the same as that in the solution, which is similar to previous reports in undoped $\mathrm{Zn}_{1-x} \mathrm{Mg}_{x} \mathrm{O}$ (Ref. 3) and Al-doped $\mathrm{ZnO}$ (Ref. 7) films, respectively. For convenience, the Mg content is always referred to that determined by EDX, while the Al content is assumed to be that in the solution, unless otherwise noted. Films had a high transmittance above $85 \%$ in visible regions. Figure 1 shows the optical transmission spectrum of a $\mathrm{Zn}_{1-x} \mathrm{Mg}_{x} \mathrm{O}$ : Al film $(x=0.11)$ as an example. The $\mathrm{Al}$ content in this film is about 4 at. \%. At this $\mathrm{Al}$ content, the lowest resistivity of $2.7 \times 10^{-3} \Omega \mathrm{cm}$ was obtained. As a TCO with a wider band gap, $\mathrm{Zn}_{1-x} \mathrm{Mg}_{x} \mathrm{O}$ is very important for the design of heterostructures, which can improve the efficiency of UV/blue light emitting devices when used as a transparent electrode.

Figure 1 also shows the optical absorption spectra of undoped $\mathrm{ZnO}$, undoped $\mathrm{Zn}_{1-x} \mathrm{Mg}_{x} \mathrm{O}$, and Al-doped $\mathrm{Zn}_{1-x} \mathrm{Mg}_{x} \mathrm{O}$ films with $x$ equal to 0.11 and $\mathrm{Al}$ content of 4 at. \%. The absorbance $(A)$ is approximately equal to $\alpha d{ }^{8}$ 


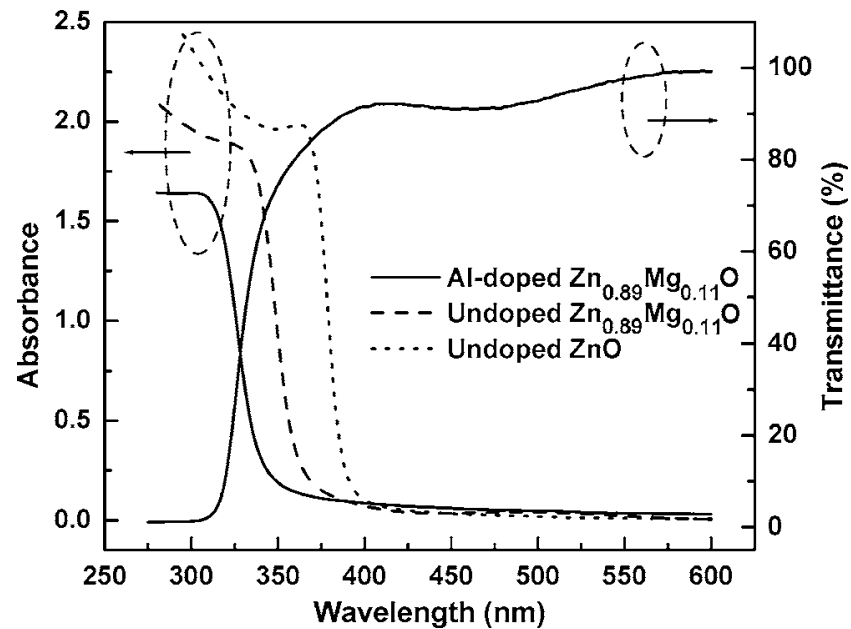

FIG. 1. Optical transmission and absorption spectra of undoped $\mathrm{ZnO}$, undoped $\mathrm{Zn}_{1-x} \mathrm{Mg}_{x} \mathrm{O}$, and $\mathrm{Al}$-doped $\mathrm{Zn}_{1-x} \mathrm{Mg}_{x} \mathrm{O}$ films. In the film $x$ equals 0.11 and the $\mathrm{Al}$ content is about 4 at. \%.

where $\alpha$ is the absorption coefficient and $d$ is the film thickness. Since we are mainly interested in measuring the optical gap of films, we have not tried to analyze in detail other issues. Taking into account the broadening effects, the transition energy can be simply deduced from the zero crossing of the second derivative of the absorption spectrum. ${ }^{8-10}$ The determined values are 3.28, 3.56, and $3.79 \mathrm{eV}$ for $\mathrm{ZnO}$, $\mathrm{Zn}_{1-x} \mathrm{Mg}_{x} \mathrm{O}$, and $\mathrm{Zn}_{1-x} \mathrm{Mg}_{x} \mathrm{O}$ : Al films, respectively. In addition to the band gap engineering in $\mathrm{ZnMgO}$ ternary alloys, there is a further increment in the energy gap of $\mathrm{ZnMgO}: \mathrm{Al}$ films as compared with the undoped ones. This blueshift is mainly related to the increase in carrier concentration owing to the introduction of $\mathrm{Al}$.

Figure 2 shows the band-gap energy as a function of the electron concentration in Al-doped $\mathrm{Zn}_{1-x} \mathrm{Mg}_{x} \mathrm{O} \quad(x=0.11)$ films. The band gaps are tuned by adjusting the carrier concentrations, which is believed to be the results of the Fermilevel band filling and band-gap renormalization effects in crystals. ${ }^{10-12}$ In the pure, undoped crystal the optical gap is equal to the energy separation $\left(E_{g 0}\right)$ between the conduction and valence band edges. In what follows we take $E_{g 0}$ $=3.56 \mathrm{eV}$ as the value of energy gap for undoped $\mathrm{Zn}_{1-x} \mathrm{Mg}_{x} \mathrm{O}(x=0.11)$, and the absorption edge shifts at high carrier concentrations in $\mathrm{Zn}_{1-x} \mathrm{Mg}_{x} \mathrm{O}: \mathrm{Al}(x=0.11)$. Films are therefore referred to this value.

In a heavily doped $n$-type semiconductor, the lowest states in the conduction band are filled with electrons when the carrier concentration increases above $N_{c}$, the conduction band density of states. $N_{c}$ is determined to be $(2.9-8.8)$ $\times 10^{18} \mathrm{~cm}^{-3}$ by assuming that $m_{e}^{*}$ equals $(0.24-0.5) m_{0}$, where $m_{e}^{*}$ is the electron effective mass at the bottom of the conduction band. According to the Burstein-Moss (BM) model,${ }^{11}$ there is a gap widening for an $n$-type semiconductor for the electron concentration $\left(n_{e}\right)$ larger than $N_{c}$. In this case, the optical gap $\left(E_{g}\right)$ of Al-doped $\mathrm{Zn}_{1-x} \mathrm{Mg}_{x} \mathrm{O}$ is the sum of the optical gap of undoped $\mathrm{Zn}_{1-x} \mathrm{Mg}_{x} \mathrm{O}$ plus the band-gap widening; that is

$$
E_{g}=E_{g 0}+\Delta E^{\mathrm{BM}}
$$

$\Delta E^{\mathrm{BM}}=\left(E_{F}-E_{C}\right)\left[1-\alpha\left(E_{F}-E_{C}\right) / E_{g}\right]$,

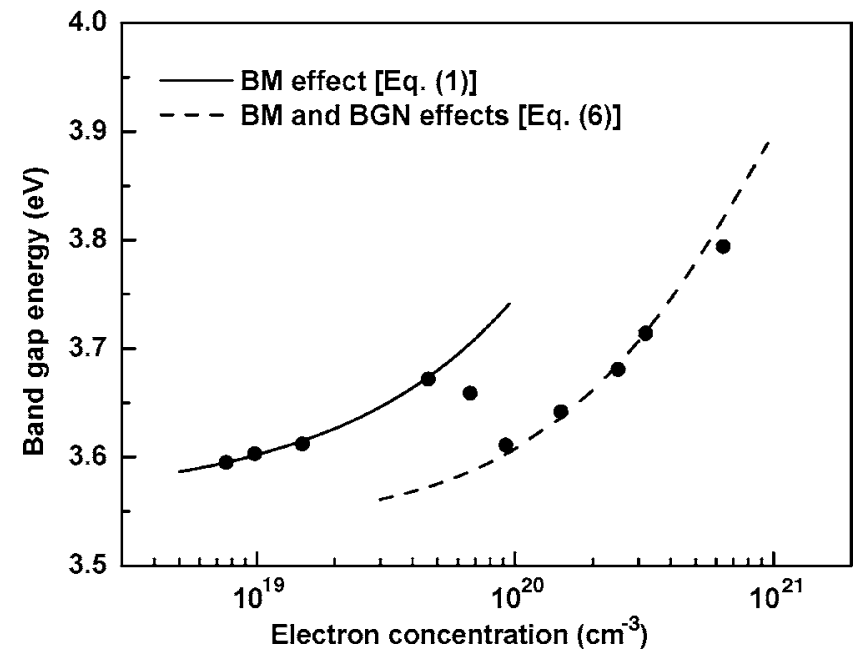

FIG. 2. Band-gap energy as a function of the electron concentration in Al-doped $\mathrm{Zn}_{1-x} \mathrm{Mg}_{x} \mathrm{O}(x=0.11)$ films. The solid and dashed lines are the fitting curves.

$$
E_{F}-E_{C}=(3 / \pi)^{2 / 3}\left(h / 8 m_{e}^{*}\right) n_{e}^{2 / 3} .
$$

Here, $E_{F}-E_{C}$ is the Fermi energy relative to the bottom of the conduction band based on an ideal parabolic band model (BM shift), $h$ is Planck's constant, $\alpha$ is a constant, and $\Delta E^{\mathrm{BM}}$ is the modified BM shift considering the nonparabolicity of the conduction band. As shown in Fig. 2 (solid line), our experimental data are fitted well by Eq. (1) in the low concentration regions, implying that this blueshift of energy gap can be fully explained by the BM theory of band filling. The fitting gives that $m_{e}^{*}=0.40 m_{0}$.

However, for concentration of $(4.6-9.2) \times 10^{19} \mathrm{~cm}^{-3} \mathrm{a}$ sudden decrease in the optical gap below that predicted by the BM theory is observed. This sudden decrease is related to a semiconductor-metal transition accompanied by a merging of the donor and conduction bands. ${ }^{10}$ It is usually assumed that the merging does not alter the $\boldsymbol{k}$ dependence of the conduction band (i.e., rigid shift of the band with no change in the electron effective mass). The Mott critical concentration $\left(n_{c}\right)$ can be estimated from various theoretical models making use of the relation ${ }^{13}$

$$
n_{c}^{1 / 3} a^{*}=K,
$$

where $a^{*}$ is the Bohr radius of the donor and $K$ varies from 0.18 to 0.376 depending on the model. The values of $K$ give $n_{c}$ values varying from $1.89 \times 10^{18}$ to $1.73 \times 10^{19} \mathrm{~cm}^{-3}$. The experimental observation is in agreement with theoretical predictions, in which the onset of gap narrowing is predicted to occur at $n_{c}-10 n_{c}{ }^{10,13}$

Above this critical concentration, the band gap increases again but at a different rate, as shown in Fig. 2. This is due to the band-gap narrowing (BGN) associated with many-body effects on the conduction and valence bands. ${ }^{12}$ This band-gap renormalization effect begins to be competitive with the $\mathrm{BM}$ effect at a high concentration. The BGN effect can be predicated by a simple theoretical expression, which has been proven to be valid in groups $\mathrm{V}$ and III-V semiconductors, ${ }^{12}$

$$
\Delta E^{\mathrm{BGN}}=A n_{e}^{1 / 3}+B n_{e}^{1 / 4}+C n_{e}^{1 / 2},
$$

where $A, B$, and $C$ are coefficients. The three terms in this expression are the exchange energy of majority carriers, correlation energy of minority carriers, and carrier-ion interac- 


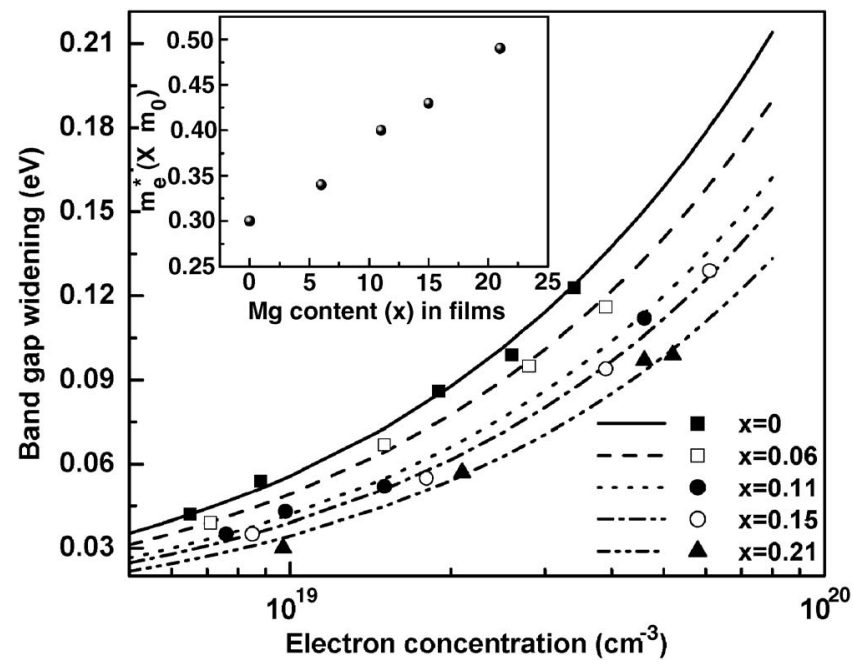

FIG. 3. Dependence of the band-gap blueshift on the carrier concentration of Al-doped $\mathrm{Zn}_{1-x} \mathrm{Mg}_{x} \mathrm{O}$ films, with $x$ increasing from 0 to 0.21 . The points are the experimental data. The curves show the fitting results using the modified BM theory. The inset shows the electron effective masses of $\mathrm{Zn}_{1-x} \mathrm{Mg}_{x} \mathrm{O}$ alloys with different $\mathrm{Mg}$ contents.

tion energy, respectively. Accordingly, the optical gap of $\mathrm{Zn}_{1-x} \mathrm{Mg}_{x} \mathrm{O}$ : Al films is determined by a combination of BM and BGN effects, the former giving a blueshift and the latter an offsetting redshift.

$$
E_{g}^{\prime}=E_{g 0}+\Delta E^{\mathrm{BM}}-\Delta E^{\mathrm{BGN}} \text {. }
$$

The dashed line in Fig. 2 is the fitting result using Eq. (6), which gives $A=1.14 \times 10^{-8} \mathrm{eV} \mathrm{cm}, B=1.27 \times 10^{-7} \mathrm{eV} \mathrm{cm}^{3 / 4}$, and $C=7.38 \times 10^{-12} \mathrm{eV} \mathrm{cm}^{3 / 2}$. The good experimental agreement (see Fig. 2), together with the simplicity of the expression, makes Eq. (5) a valuable tool for semiconductor device modeling.

We have also studied the modified BM shifts of $\mathrm{Zn}_{1-x} \mathrm{Mg}_{x} \mathrm{O}$ alloys with different $\mathrm{Mg}$ contents. Figure 3 shows the calculated curves in the relatively low concentration regions, in which only the BM effect is considered. Since the electron effective masses of $\mathrm{Zn}_{1-x} \mathrm{Mg}_{x} \mathrm{O}$ are still unknown, we treat them as the fitting parameters. The $m_{e}^{*}$ values thus obtained are shown in the inset of Fig. 3, increasing from $0.30 m_{0}$ to $0.49 m_{0}$ as $x$ is up from 0 to 0.21 . The experimental data suggest that the effective mass in $\mathrm{Zn}_{1-x} \mathrm{Mg}_{x} \mathrm{O}$ is substantially enlarged with alloying of $\mathrm{ZnO}$ with $\mathrm{MgO}$.

Figure 4 illustrates the electrical properties of $\mathrm{Zn}_{1-x} \mathrm{Mg}_{x} \mathrm{O}: \mathrm{Al}(x=0-0.21)$ films. The Al contents are about 4 at. $\%$ in all the films. The resistivity increases with increasing $\mathrm{Mg}$ content in films, while the carrier mobility and concentration decrease. It seems that the doping efficiency is reduced with the $\mathrm{Mg}$ content. The detailed explanations for this degradation are unfeasible at present, but we can consider several possible reasons. Firstly, the electron effective mass becomes larger as identified above, which increases the donor activation energy and so decreases the ionization of dopant. Secondly, the alloy scattering is enhanced with the

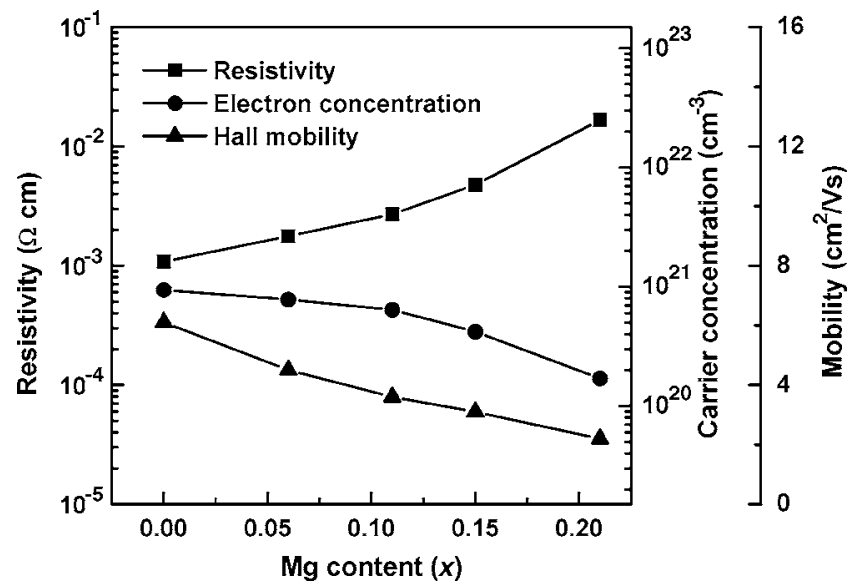

FIG. 4. Resistivity, Hall mobility, and electron concentration of $\mathrm{Zn}_{1-x} \mathrm{Mg}_{x} \mathrm{O}: \mathrm{Al}(x=0-0.21)$ films. The $\mathrm{Al}$ contents in these films are about 4 at. $\%$.

alloy composition, which has a significant effect on the mobility. Thirdly, clusters such as magnesium aluminate may be present in films, ${ }^{14}$ which prevents $\mathrm{Al}$ from acting as an electron donor.

In summary, transparent conducting $\mathrm{Zn}_{1-x} \mathrm{Mg}_{x} \mathrm{O}: \mathrm{Al}$ films have been prepared by a CVD system. The dependence of the band-gap shift on carrier concentration was systematically investigated. This study is expected not only to provide an insight into the fundamental understanding of the optical and electrical properties of $\mathrm{Zn}_{1-x} \mathrm{Mg}_{x} \mathrm{O}$ alloys but also to make a significant technical advance on the optoelectronic device fabrication in this system.

This work was supported by the Grant-in-Aid for Scientific Research for JSPS Postdoctoral Program for Foreign Researchers P05329.

${ }^{1}$ Z. K. Tang, G. K. L. Wong, P. Yu, M. Kawasaki, A. Ohtomo, H. Koinuma, and Y. Segawa, Appl. Phys. Lett. 72, 3270 (1998).

${ }^{2}$ J. G. Lu, Y. Z. Zhang, Z. Z. Ye, L. P. Zhu, L. Wang, B. H. Zhao, and Q. L. Liang, Appl. Phys. Lett. 88, 222114 (2006).

${ }^{3}$ A. Ohtomo, M. Kawasaki, T. Koida, K. Masubuchi, H. Koinuma, Y. Sakurai, Y. Yoshida, T. Yasuda, and Y. Segawa, Appl. Phys. Lett. 72, 2466 (1998).

${ }^{4}$ L. Zou, Z. Z. Ye, J. Y. Huang, and B. H. Zhao, Chin. Phys. Lett. 19, 1350 (2002).

${ }^{5}$ H. Tanaka, Sg. Fujita, and Sz. Fujita, Appl. Phys. Lett. 86, 192911 (2005).

${ }^{6}$ K. Matsubara, H. Tampo, H. Shibata, A. Yamada, P. Fons, K. Iwata, and S. Niki, Appl. Phys. Lett. 85, 1374 (2004).

${ }^{7}$ J. G. Lu, Z. Z. Ye, Y. J. Zeng, L. P. Zhu, L. Wang, J. Yuan, B. H. Zhao, and Q. L. Liang, J. Appl. Phys. 100, 073714 (2006).

${ }^{8}$ S. Barik, A. K. Srivastava, P. Misra, R. V. Nandedkar, and L. M. Kukreja, Solid State Commun. 127, 463 (2003).

${ }^{9}$ S. Srinivasan, F. Bertram, A. Bell, F. A. Ponce, S. Tanaka, H. Omiya, and Y. Nakagawa, Appl. Phys. Lett. 80, 550 (2002).

${ }^{10}$ A. P. Roth, J. B. Webb, and D. F. Williams, Phys. Rev. B 25, 7836 (1982).

${ }^{11}$ E. Burstein, Phys. Rev. 93, 632 (1954).

${ }^{12}$ S. C. Jain, J. M. McGregor, and D. J. Roulston, J. Appl. Phys. 68, 3747 (1990).

${ }^{13}$ T. G. Castner, N. K. Lee, G. S. Cieloszyk, and G. L. Salinger, Phys. Rev. Lett. 34, 1627 (1975).

${ }^{14}$ D. J. Cohen, K. C. Ruthe, and S. A. Barnett, J. Appl. Phys. 96, 459 (2004). 